\title{
Distinctive characteristics of subclasses of red-green P-cells in LGN of macaque
}

\author{
MARTIN J.M. LANKHEET, PETER LENNIE, AND JOHN KRAUSKOPF \\ Center for Visual Science, University of Rochester, Rochester \\ (Received September 5, 1996; Accepted July 8, 1997)
}

\begin{abstract}
We characterized the chromatic and temporal properties of a sample of 177 red-green parvocellular neurons in the LGN of Macaca nemestrina, using large-field stimuli modulated along different directions through a white point in color space. We examined differences among the properties of the four subclasses of red-green P-cells (on- and off-center, red and green center). The responses of off-center cells lag the stimulus more than do those of on-center cells. At low temporal frequencies, this causes the phase difference between responses of the two kinds of cells to be considerably less than $180 \mathrm{deg}$. For isoluminant modulations the phases of on- and off-responses were more nearly $180 \mathrm{deg}$ apart. A cell's temporal characteristics did not depend on the class of cone driving its center. Red center and green center cells have characteristically different chromatic properties, expressed either as preferred elevations in color space, or as weights with which cells combine inputs from L- and M-cones. Red center cells are relatively more responsive to achromatic modulation, and attach relatively more weight to input from the cones driving the center. Off-center cells also attach relatively more weight than do on-center cells to input from the class of cone driving the center.
\end{abstract}

Keywords: P-cells, Lateral geniculate nucleus (LGN), Macaque monkey, Chromatic properties, Temporal properties

\section{Introduction}

Retinal circuits that connect cones to on- and off-center midget ganglion cells differ in the connections between bipolar cells and cones, and in the connections between bipolar cells and ganglion cells. The on-center pathway begins in midget bipolar cells that make sign-inverting synapses with cone pedicles (Stell et al., 1977), and have axon terminals in the sclerad part of the inner plexiform layer (Famiglietti \& Kolb, 1976). The off-center pathway begins in midget bipolar cells that make sign-conserving contacts with cone pedicles, and have axon terminals in the vitread part of the inner plexiform layer. In the fovea, every cone contributes to both pathways.

Recent anatomical evidence points to further structural differences among pathways that might be associated with inputs from different kinds of cones. Kouyama and Marshak (1992) described a distinctive invaginating bipolar cell that contacts only S-cones (there are also flat contacts on S-cones but no counterpart bipolar cell has been identified). Calkins et al. (1994) found that, within each of the separate on- and off-pathways, the number of synaptic connections a midget bipolar cell made with a midget ganglion fell

Reprint requests to: Martin J.M. Lankheet, Department of Comparative Physiology and Helmholtz Institute, Universiteit Utrecht, Padualaan 8, $3584 \mathrm{CH}$ Utrecht, The Netherlands.

Present address of John Krauskopf: Center for Neural Science, New York University, New York, NY 10003, USA. into one of two nonoverlapping distributions. The bipolar cells making the two kinds of connections were randomly distributed on the retina. Among the bipolar cells studied, 44\% had the larger number of synaptic ribbons. These different kinds of synaptic connections suggested differences between the pathways conveying signals from L- and M-cones, though they did not indicate which kind of cone was associated with each pathway.

Different arrangements of connections and different strengths of connections in pathways between cones and ganglion cells raise the possibility that on- and off-center ganglion cells behave differently, and that further differences in behavior might depend on the classes of cones that drive them. P-cells in the LGN fall into two chromatic groups: red-green cells and blue-yellow cells. Redgreen cells receive opposed inputs from L- and M-cones only; blue-yellow cells receive opponent input from S-cones and a combination of L- and M-cones (Derrington et al., 1984). One might expect differences between circuits to be expressed most visibly in the relative strengths of contributions from different classes of cones to center and surround, and in the dynamics of centersurround interaction. There is no indication that L- and M-cones themselves have different dynamics (Schnapf et al., 1990).

Chromatic opponency varies among P-cells, and is known to decline with increasing temporal frequency (Gouras \& Zrenner, 1979; Derrington et al., 1984; Smith et al., 1992). Little attention has been paid to differences between subclasses of red-green P-cells, but where this has been examined (Gielen et al., 1982; Lee et al., 1990; Yeh et al., 1995; Smith et al., 1992; Croner \& Kaplan, 1995) 
no consequential differences have been reported. We have examined the chromatic characteristics of a large sample of red-green P-cells, by measuring responses to modulation of color and luminance about a white point (Derrington et al., 1984). We find that cell properties vary systematically with the type of cone input to the center. Furthermore, we find clear differences between temporal characteristics of on- and off-center neurons.

\section{Methods}

\section{Preparation and recording}

The discharges of P-cells were recorded in the lateral geniculate nucleus (LGN) of seven Macaca nemestrina that weighed between 3.0 and $4.5 \mathrm{~kg}$. Anesthesia was induced with an injection of ketamine hydrochloride (Vetalar, $10 \mathrm{mg} / \mathrm{kg}$, i.m.). Cannulae for infusion were inserted in the saphenous veins and the trachea was cannulated. After the initial surgery, anesthesia was maintained with sufentanil citrate (Sufenta) administered intravenously to effect. Because Sufenta often caused severe respiratory depression, animals were artificially respired after starting the administration of Sufenta. The head was mounted in a stereotaxic frame and an 8-mm craniotomy was made above the right lateral geniculate body, centered near HC coordinates 9 anterior, 11 lateral. The dura was not removed. After positioning the electrode carrier, the hole was covered with agar and sealed with dental cement.

During the experiment, anesthesia was maintained by a continuous infusion of Sufenta (initially $3 \mu \mathrm{g} / \mathrm{kg} / \mathrm{h}$ ). The adequacy of this dose was first assessed by monitoring the depth of anesthesia for $3 \mathrm{~h}$ before administering muscle relaxant; if the animal could be aroused, or showed signs of distress, the dose was increased. In two cases, the dose was increased to 4 or $5 \mu \mathrm{g} / \mathrm{kg} / \mathrm{h}$. During recording, the level of anesthesia was checked continuously by monitoring the electroencephalogram (EEG) and the electrocardiogram (ECG). Before recording, paralysis was induced by a $50 \mu \mathrm{g} / \mathrm{kg}$ loading dose of vecuronium bromide (Norcuron) and maintained by a continuous infusion $(100 \mu \mathrm{g} / \mathrm{kg} / \mathrm{h})$ in lactated Ringer's solution with dextrose. The end-tidal $\mathrm{PCO}_{2}$ was monitored continuously, and kept near $4 \%$ by adjusting the respiratory volume when necessary. Body temperature was measured with a subscapular thermistor and was maintained near $37^{\circ} \mathrm{C}$ by a heating blanket.

Pupils were dilated with atropine sulfate. The corneas were protected with gas permeable contact lenses and supplementary lenses were used to focus stimuli on the retinas. Artificial pupils $3 \mathrm{~mm}$ in diameter were placed directly in front of the contact lenses. The eyes were examined regularly during the experiment and closed without contact lenses for several hours each night. Ophthalmic neosporin solution was applied regularly to prevent eye infections. A reversed ophthalmoscope was used to mark the positions of the foveas on a tangent screen in front of the animal; the positions of the foveas were replotted each time the contact lenses were replaced.

Action potentials were recorded from single units with platinumtipped glass-insulated tungsten microelectrodes. An electrode, contained within a hypodermic guide needle, was advanced manually to several millimeters above the LGN and subsequently moved out of the guide needle with a stepping motor-driven micrometer. The amplified signals recorded by the electrode were sampled at 10 $\mathrm{kHz}$ by a Macintosh Quadra 950 computer using a multifunction IO board (National Instruments, Austin, TX; NB-MIO16). Digitized signals were analyzed by a digital signal processor (DSP)
(National Instruments, Austin, TX; NB-DSP2305). Candidate action potentials, identified provisionally by threshold crossings, were compared with a template. If the match was within a specified tolerance, the spike time (measured to the nearest $100 \mu \mathrm{s}$ ) was placed directly in a buffer in the Macintosh. For clearly isolated single spikes, the template was formed from the average of 15 sample waveforms; this procedure could be repeated iteratively if necessary. When two or more spikes were present, the DSP could undertake a cluster analysis to construct a template for each. Although the DSP could deal with up to eight spikes concurrently, we never worked with more than three, and almost always with one.

\section{Visual stimuli}

All stimuli were large-field sinusoidal modulations of chromaticity and/or luminance about a steady adaptation level (close to equalenergy white). We represent these, and the chromatic characteristics of P-cells, in two different ways. One representation employs a three-dimensional color space used by Derrington et al. (1984), and is based upon a chromaticity diagram developed by MacLeod and Boynton (1979). An isoluminant plane passing through the adaptation point (the origin) is defined by two chromatic axes (Fig. 1). Modulation along the $\mathrm{L}-\mathrm{M}$ axis brings about no change in the excitation of S-cones while the excitations of $\mathrm{L}$ - and $\mathrm{M}$-cones covary so as to keep their sum constant. Modulation along the orthogonal $\mathrm{S}$-axis excites only the $\mathrm{S}$-cones. Modulation along the third, achromatic, axis changes excitation in all three cone types in equal proportion. What we now call the $\mathrm{L}-\mathrm{M}$ axis was in earlier work (Derrington et al., 1984) referred to as the "constant B" axis, and what we now call the S-axis was referred to as the "constant R-G," or "tritanopic" axis.

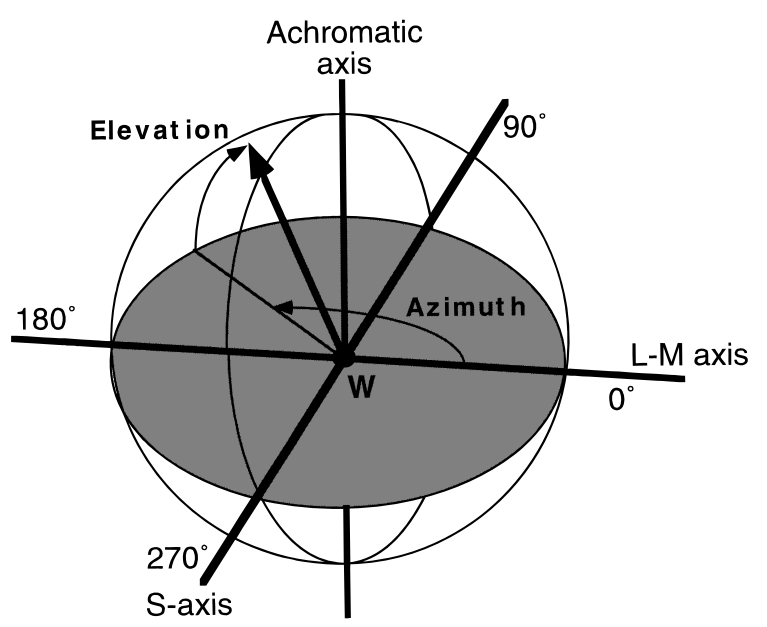

Fig. 1. Three-dimensional color space in which we represent stimuli and chromatic properties of cells. Along the L-M axis the excitation of M- and L-cones covaries so as to keep their sum constant. Along the orthogonal $\mathrm{S}$-axis only the excitation of S-cones varies. Along the achromatic axis the excitation of all three types of cones varies in equal proportion. Stimuli consisted of sinusoidal modulations along a vector through the white point (W). A vector is described by its azimuth and elevation. The azimuth describes the rotation in the isoluminant plane relative to the positive (red) end of the $\mathrm{L}-\mathrm{M}$ axis. The elevation is the rotation out of the isoluminant plane. Cells that combine signals from different cone types linearly can be characterized by a vector in this color space along which they are maximally sensitive to modulation, or alternatively by a null-plane in which modulations cause no response. 
Loci in this space are represented by polar coordinates. The azimuth $(A)$ is the angle in the isoluminant plane, referred to the "red" pole of the L-M axis; the elevation $(E)$ describes the rotation out of the isoluminant plane. All stimuli were sinusoidal modulations along vectors through the white point, with mean luminance and mean chromaticity set at the white point. The length of the vector defined the contrast.

The color space in Fig. 1 provides a convenient vehicle for expressing the chromatic characteristics of cells in ways that can be compared with the properties of second-stage mechanisms of color vision identified psychophysically (Krauskopf et al., 1982, 1986; Webster \& Mollon, 1991), but it is a less useful vehicle for expressing the strengths of inputs a cell receives from individual classes of cones. For this reason, we also represent the properties of cells by the weights they attach to signals from the different classes of cones.

Stimuli were generated by the computer and displayed on a Nanao T560i monitor, controlled by a Rasterops Procolor 32 video board that provided 9-bit resolution of intensity for the red, green, and blue guns. The monitor had NTSC phosphors and was refreshed (progressive scan) at $75 \mathrm{~Hz}$. Table 1 shows the CIE chromaticity coordinates of the phosphors and the white point. The mean luminance of the display was $48 \mathrm{~cd} / \mathrm{m}^{2}$. Viewed through the 3-mm diameter pupil this provided, in the monkey's eye, a retinal illuminance equivalent to $570 \mathrm{td}$ in the larger human eye. This was high enough to escape rod intrusion.

Relative cone excitations produced by the monitor were calculated from spectral emission measurements on the individual phosphors, made at 10-nm intervals between 400 and $700 \mathrm{~nm}$, and using Smith and Pokorny's (1975) estimates of the human cone fundamental sensitivities. The isoluminant plane of the color space was calculated using Judd's (1951) correction to $V \lambda$. In representing stimuli in the color space of Fig. 1, unit contrast along the achromatic axis corresponds to a Michelson contrast of 1 . Unit contrast along the isoluminant axes is equal to the maximum attainable modulation. Along the $\mathrm{L}-\mathrm{M}$ axis, this corresponds to a Michelson contrast of 0.0834 to the L-cones and 0.159 to the M-cones. The difference between L- and M-cone modulations results from the larger weight assigned to L-cones in the calculation of luminosity. Unit modulation along the S-axis produces a contrast of 0.830 for the S-cones. The monitor, viewed via a frontsurface mirror, was placed either $57 \mathrm{~cm}$ or $171 \mathrm{~cm}$ from the monkey's eye. At the latter distance the screen subtended $9.8 \mathrm{deg} \times 7.5 \mathrm{deg}$.

\section{Procedure}

We recorded from P-cells with receptive fields in the fovea and parafovea, usually at eccentricities less than $3 \mathrm{deg}$. Receptive fields, initially hand-plotted on a tangent screen, were centered on the monitor with the help of a laser pointer. A cell's chromatic prop-

Table 1. CIE coordinates of the phosphors of the television display, and of the white point used in the experiments

\begin{tabular}{lcc}
\hline \hline & $x$ & $y$ \\
\hline Red & 0.6219 & 0.3329 \\
Green & 0.2814 & 0.5944 \\
Blue & 0.1449 & 0.0568 \\
White & 0.3087 & 0.3141 \\
& & \\
\hline \hline
\end{tabular}

erties were characterized by recording the responses to large-field modulations along nine directions in color space: azimuth values at 45-deg intervals in the isoluminant plane and 90-deg intervals at elevations of $\pm 45 \mathrm{deg}$. Achromatic modulation and a blank control completed the set. Stimuli lasted $2 \mathrm{~s}$ and were repeated between 10 and 20 times, in balanced pseudorandom order. Stimuli were modulated at $4 \mathrm{~Hz}$, a compromise between higher frequencies that yield increased responsivity at the expense of decreased color opponency (as a result of an increasing phase difference between center and surround contributions to response), and lower frequencies that yield poorer responsivity. The accompanying paper (Lankheet et al., 1998) explores this issue fully.

At low temporal frequencies, responses vary sinusoidally with the angle of the stimulus vector in any plane in color space. The chromatic properties of P-cells can therefore be described by finding the preferred azimuth and elevation (Derrington et al., 1984). Orthogonal to this preferred direction is a null-plane in which modulations are invisible to the cell.* To estimate the neuron's preferred direction in color space, we first used the linear model introduced by Derrington et al. (1984) to characterize the first harmonic component of response. The response amplitude $(R)$ as a function of elevation $(E l)$ and azimuth $(A z)$ is given by

$$
R=S\left[\sin E l \sin E l_{p}+\cos E l \cos E l_{p} \cos \left(A z-A z_{p}\right)\right]
$$

where $E l_{p}$ and $A z_{p}$ are the preferred elevation and azimuth, respectively, and $S$ describes the overall sensitivity.

This analysis assumes linearity of responses and uniform temporal properties of cone inputs. Since we fit the model to a complete data set, small deviations from linearity for the largest responses have little effect on chromatic tuning. In the accompanying paper, we show that the phase of the response does vary with stimulus chromaticity, but at the frequency used here $(4 \mathrm{~Hz})$ this has negligible effect on the estimate of the cell's preferred direction (Lankheet et al., 1998).

\section{Results}

Throughout this paper, we distinguish the responses of neurons (the stream of action potentials it discharges) and the signals in the center and surround pathways that ultimately give rise to these responses. We conceive of the signals as covert responses that could in principle be recorded.

\section{Cell classification}

Fig. 2 shows responses of an on-center red-green cell to spatially uniform fields modulated sinusoidally at $4 \mathrm{~Hz}$ along different directions in color space. The contrast of each stimulus was set to the maximum attainable along that direction in color space. The upper left panel shows the spontaneous activity in the presence of an unmodulated field at the white point. Histograms show mostly sinusoidal responses with small nonlinear contributions from higher harmonics. Contrast-response functions for P-cells were always reasonably linear up to the highest contrast levels we used. Our results thus confirm previous reports (Kaplan \& Shapley, 1982; Derrington \& Lennie, 1984) that LGN P-cells show little response compression, even at the highest contrast levels. In Fig. 2B, the amplitudes of the first harmonic components of responses are plot-

*We use the preferred direction in color space as the signature of a cell, while Derrington et al. (1984) used the location of its null-plane. 

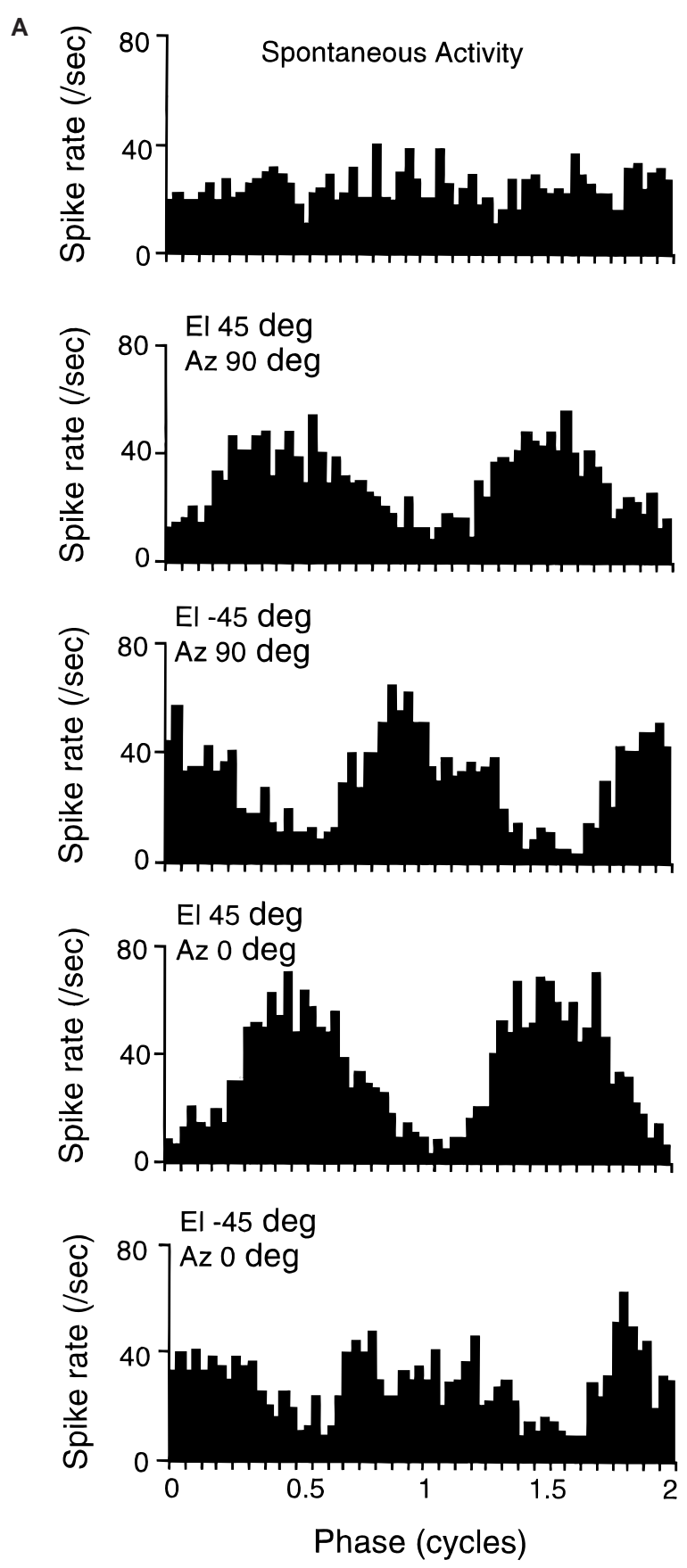
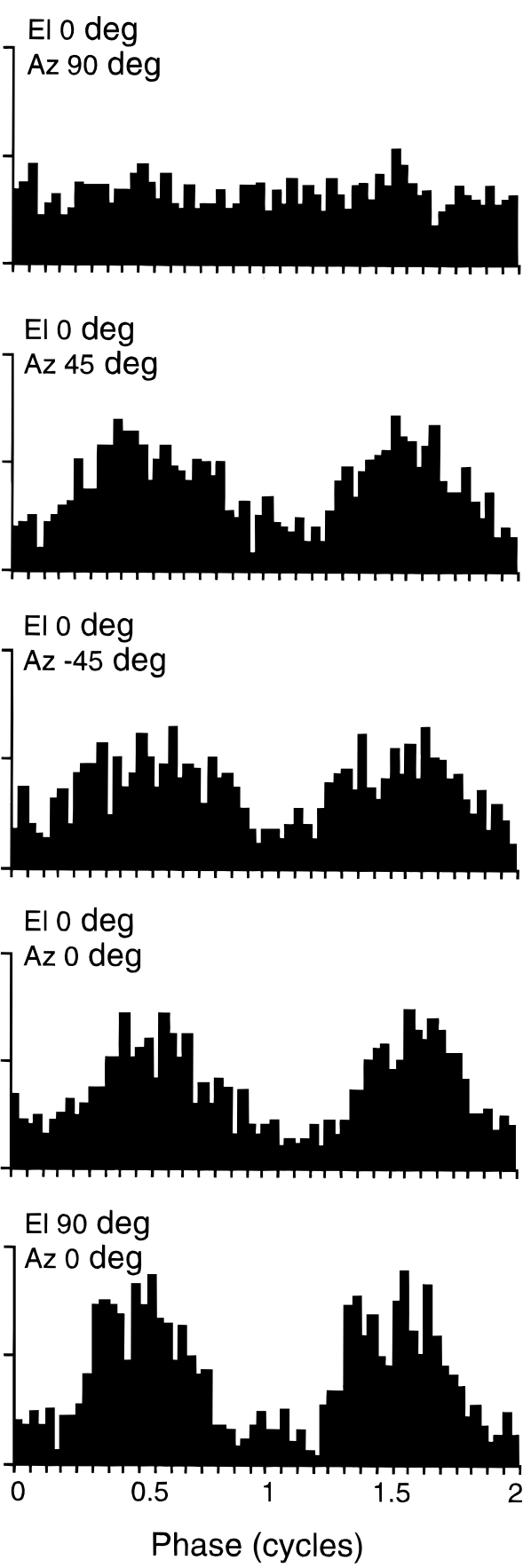

Fig. 2A. (Figure continues on facing page.)

ted as a function of elevation and azimuth. The smooth curves show the linear model [eqn. (1)] fitted to the data. Blue-yellow cells and red-green cells were identified by their preferred azimuth (Derrington et al., 1984). Azimuths of blue-yellow cells, which were encountered much less often, cluster around 90 and 270 deg (S-axis). Of a total sample of 222 cells, 45 cells were identified as blue-yellow. This paper discusses only red-green cells, with characteristic azimuths falling within $\pm 45 \mathrm{deg}$ of the $\mathrm{L}-\mathrm{M}$ axis.

Cells were classified as either on-center or off-center by the polarity of their response (on or off) to achromatic modulations. Fig. 3 shows for 177 red-green cells the distribution of temporal phases to both achromatic and isoluminant $\mathrm{L}-\mathrm{M}$ modulations (at
$4 \mathrm{~Hz})$ $\dagger$ The cells fall into four different groups, corresponding to the four different subclasses. At the frequency we used to characterize the chromatic properties, P-cell responses typically show a phase lag relative to modulation of an achromatic stimulus. This is

$\dagger$ In the convention we use to represent the phase of the response, a negative phase represents a delay in relation to the stimulus. Were there no delay between stimulus and response, we would expect an on-center cell stimulated by achromatic modulation to have a response phase of $0 \mathrm{deg}$, and an off-center cell a response phase of $180 \mathrm{deg}$. A red on cell when stimulated by L-M modulation would be expected have a response phase of $0 \mathrm{deg}$, and green on cell a response phase of $180 \mathrm{deg}$. 


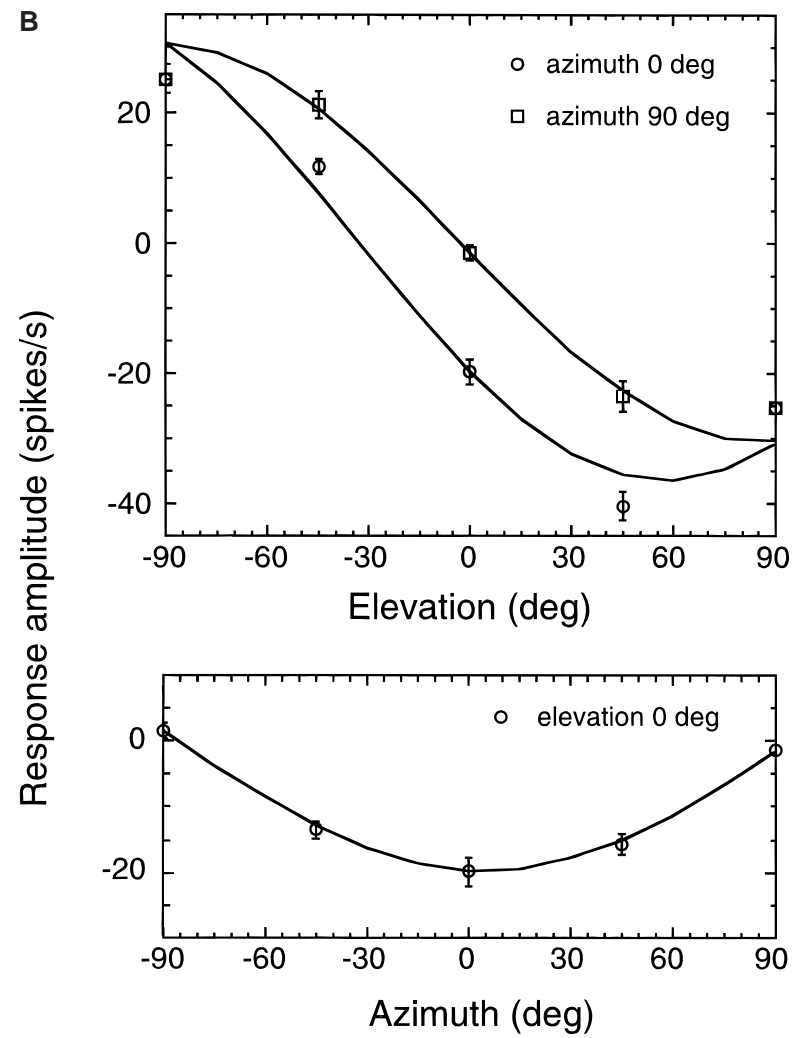

Fig. 2. A: Poststimulus time histograms of responses of an on-center redgreen cell to 4-Hz modulation of a spatially uniform field along different directions in the color space shown in Fig. 1. B: Amplitudes of the first harmonic component of response, derived from the histograms in A. The lines are best-fitting solutions to eqn. (1) (see diagram of Fig. $2 \mathrm{~A}$ on facing page).

clear in the histograms, which show the distributions collapsed separately for achromatic modulation and L-M modulation. At $4 \mathrm{~Hz}$, a phase of $+40 \mathrm{deg}$ was found optimally to partition cells into two clusters. We classified cells as on-center if the phase of the response to achromatic modulation fell between $+40 \mathrm{deg}$ and $-140 \mathrm{deg}$ and as off-center otherwise. On-center cells have positive elevations, off-center cells negative elevations.

To identify the four subtypes of red-green cells, we compared the temporal phases of responses to achromatic and isoluminant modulations. If responses were approximately in-phase, L-cone input was attributed to the center and the cell was identified as a red center cell. If the center response and the L-cone response were out of phase, the cell was identified as a green center cell. The underlying assumption (which we have checked on many cells) is that to large-field achromatic stimuli the responses are dominated by the center mechanism, i.e. the center has a larger gain than the surround.

Fig. 4A shows the distribution of preferred elevations and azimuths among the sample of 177 red-green cells. Notice that the spherical distribution is shown in an orthogonal projection. At elevations near the poles this overemphasizes the differences among azimuths: differences in azimuth are of little relevance at extreme elevations, and are undefined at the poles. The model generally fits the responses well; the mean RMS error was $11.9 \%$, at a mean sensitivity $[S$ in eqn. (1)] of 35 impulses/s. To estimate the reliability of the fitted values, we calculated the standard error for estimates of elevation and azimuth obtained trial-by-trial for the individual sets of measurements that made up the series normally folded into the histograms. The average standard error for estimates of elevation was $2.3 \mathrm{deg}$, and for almost all cells was less than $5 \mathrm{deg}$. The mean standard error of the azimuth was similar near the isoluminant plane but increased with elevation.

The preferred azimuths of red-green P-cells cluster around the L-M axis. Red on-center cells and green off-center cells fall around an azimuth of $0 \mathrm{deg}$. Red off-center cells and green on-center cells fall around an azimuth of $180 \mathrm{deg}$. We found no systematic deviation in azimuth that would indicate consequential input from S-cones (Wooten \& Werner, 1979). The mean azimuths deviated 0.8 and 0.2 deg from the L-M axis for red and green center cells, respectively. The deviations of preferred azimuths from the chromatic axes are small near the isoluminant plane, but increase with elevation, as would be expected for this projection of the data. Fig. 4B shows distributions of azimuth and elevation separately for the four subtypes of red-green cell.

\section{Distinctive characteristics of red-green subclasses}

Fig. 3 shows that responses of on- and off-center cells to achromatic modulations are not simply $180 \mathrm{deg}$ out of phase. The mean phase of the response of on-center cells was $-36.6 \mathrm{deg}$, whereas that of off-center cells was $118.7 \mathrm{deg}$, or $-61.3 \mathrm{deg}$ in relation to the stimulus that excites the center. The mean phase difference (155.3 deg) and median phase difference (150 deg) were similar, indicating that the difference between on- and off-center cells cannot be attributed to the behavior of outliers. Thus, on- and offcenter cells differ not only in sign of response but also in the temporal properties of their underlying mechanisms. These differences were observed only for achromatic modulations. For isoluminant modulations, the different subclasses responded more nearly in phase (red on-center and green off-center, red off-center and green on-center) or in counterphase (red on-center and green oncenter, red off-center and green off-center). The type of cone providing input to the center had little effect on the temporal characteristics of a cell. Among on-center cells, the phases of responses of red and green cells to achromatic flicker were $-38.0 \mathrm{deg}$ and $-35.3 \mathrm{deg}$ on average; to isoluminant flicker the phases of responses were $-75.0 \mathrm{deg}$ and $102.8 \mathrm{deg}$ (a difference of $177.8 \mathrm{deg}$ ). Among off-center cells, the average phases of responses of red and green cells to achromatic flicker were $121.0 \mathrm{deg}$ and $116.1 \mathrm{deg}$, respectively, and to isoluminant flicker $114.8 \mathrm{deg}$ and $-72.3 \mathrm{deg}$ (a difference of $187.1 \mathrm{deg}$ ).

The broad range of elevations shown in Fig. 4 shows that the balance of cone inputs varies among P-cells. This agrees with earlier findings (De Valois et al., 1966; Padmos \& Norren, 1975; de Monasterio \& Gouras, 1975; Dreher et al., 1976; Derrington et al., 1984). The distributions of elevations are unimodal, and provide no indication that there exist separate populations of weakly and strongly opponent cells (Wiesel \& Hubel, 1966; Valberg et al., 1987). The distributions do, however, differ distinctively among subclasses of red-green cells.

Fig. 4 shows that the distributions of preferred elevations for red center cells encompass higher elevations than those for green center cells, which are more evenly distributed over the full range. The histograms in Fig. 4B show this particularly clearly. To examine the significance of differences between subclasses, we used the Mann-Whitney $U$ test, which is sensitive to differences between median values of two distributions, to compare distributions collapsed in different ways. The median (unsigned) elevation for red center cells was $61 \mathrm{deg}$, and for green center cells $46 \mathrm{deg}$, a 


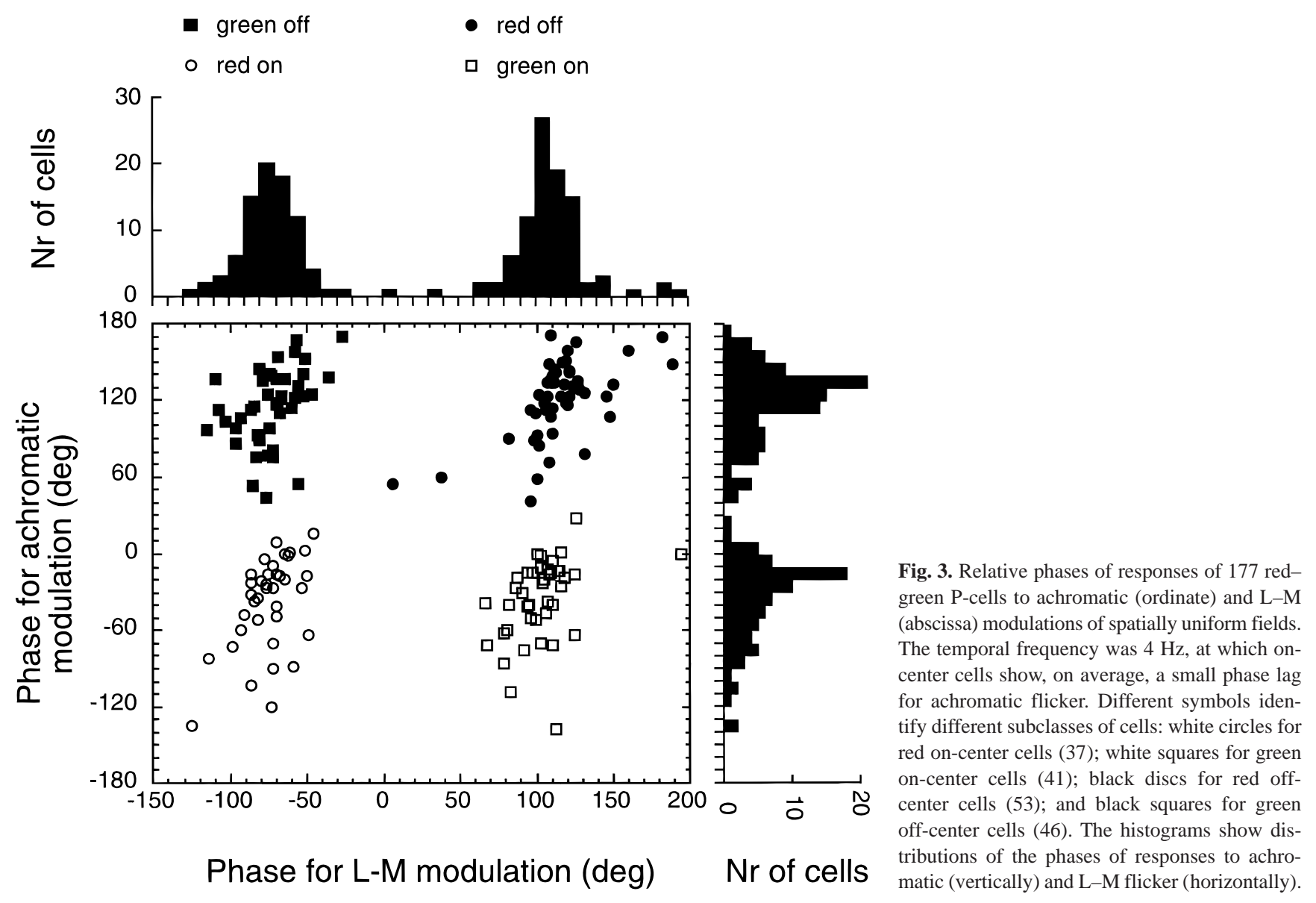

significant difference $(P<0.001)$. The difference is most conspicuous between red off-center cells and green on-center cells $(P<$ $0.001)$, less so for red and green on-center cells $(P<0.02)$, and red and green off-center cells $(P<0.03)$. There was no significant difference between the median elevations of on-center and offcenter cells. The mean azimuths, corrected for a 180-deg phase shift, did not differ significantly among red-green subclasses.

On- and off-center cells did not differ significantly in sensitivity, nor did red center and green center cells. Red off-center cells were slightly (and significantly) more sensitive than red on-center ones. This corroborates to some extent Valberg et al.'s (1987) observation that off-center P-cells were more sensitive than oncenter ones.

\section{Relative weights of cone inputs}

By representing chromatic signatures in terms of azimuth and elevation, we have a convenient way to characterize preferred stimuli, and to recognize classes of cells. However, this representation makes it hard to see the organization of inputs from the different classes of cones. The weights with which a cell combines inputs from different classes of cones can be obtained from azimuth and elevation by linear transformation (Derrington et al., 1984). This transformation assumes that phase differences between cone inputs have negligible effect on the preferred direction at the temporal frequency $(4 \mathrm{~Hz})$ used in the experiments. The accompanying paper explores the effects of temporal frequency on chromatic tuning, and validates this assumption (Lankheet et al., 1998). Because red-green cells have negligibly small inputs from S-cones we can calculate the L- and M-cone weights by collapsing the threedimensional color space to a two-dimensional one in which modulations, and a cell's preferred directions, are fully determined by the elevation and contrast.

Fig. 5 shows how the relative contributions of the L- and M-cones vary with a cell's preferred elevation. This plot was derived by applying the principle that cells are unresponsive to modulations in the plane perpendicular to the preferred direction, embodied in eqn. (2):

$$
\mathrm{w}_{\mathrm{l}}\left(E l_{p}\right) 1\left(E l_{p}-90\right)+\mathrm{w}_{\mathrm{m}}\left(E l_{p}\right) \mathrm{m}\left(E l_{p}-90\right)=0
$$

where $\mathrm{w}_{\mathrm{l}}\left(E l_{p}\right)$ and $\mathrm{w}_{\mathrm{m}}\left(E l_{p}\right)$ are the weights assigned to the L- and M-cones, respectively, by a cell whose preferred elevation is $E l_{p}$, and $1\left(E l_{p}-90\right)$ and $\mathrm{m}\left(E l_{p}-90\right)$ are the modulations $(\Delta L / L$ and $\Delta M / M)$ of the L- and M-cones, generated by stimulus variation along the direction $E l_{p}-90$. This can be rewritten as

$$
\mathrm{w}_{\mathrm{l}}\left(E l_{p}\right) / \mathrm{w}_{\mathrm{m}}\left(E l_{p}\right)=-\mathrm{m}\left(E l_{p}-90\right) / \mathrm{l}\left(E l_{p}-90\right)
$$

and the normalized weights $\mathrm{W}_{\mathrm{l}}\left(E l_{p}\right)$ and $\mathrm{W}_{\mathrm{m}}\left(E l_{p}\right)$ assigned to the $\mathrm{L}-$ and $\mathrm{M}$-cones, respectively, are given by

$$
\begin{gathered}
\mathrm{W}_{\mathrm{l}}\left(E l_{p}\right)=-\mathrm{m}\left(E l_{p}-90\right) /\left[\left|1\left(E l_{p}-90\right)\right|+\left|\mathrm{m}\left(E l_{p}-90\right)\right|\right] \\
\mathrm{W}_{\mathrm{m}}\left(E l_{p}\right)=1\left(E l_{p}-90\right) /\left[\left|1\left(E l_{p}-90\right)\right|+\left|\mathrm{m}\left(E l_{p}-90\right)\right|\right]
\end{gathered}
$$

To derive $1\left(E l_{p}-90\right)$ and $\mathrm{m}\left(E l_{p}-90\right)$, we note that the excitations of the L- and M-cones are in the ratio of 2:1 for an equal- 
A
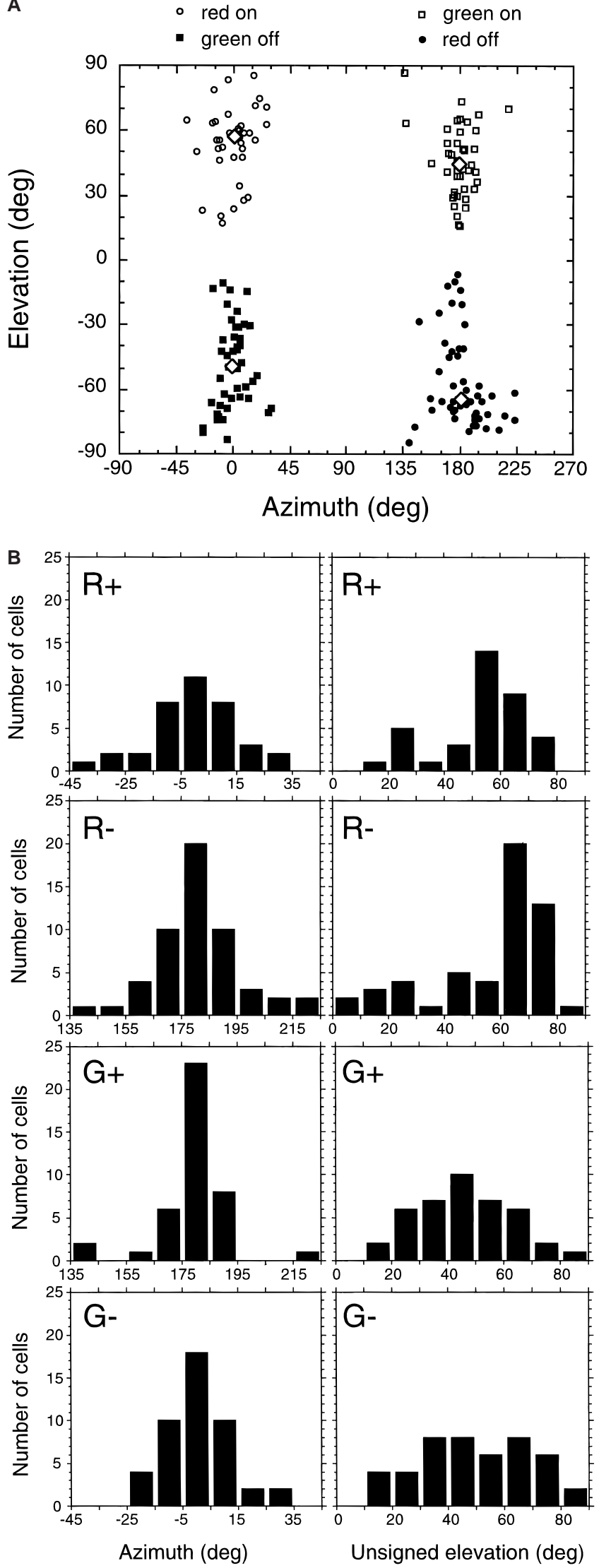

energy white in the MacLeod-Boynton (1979) chromaticity diagram which in turn uses the fundamental cone sensitivities derived by Smith and Pokorny (1975). Therefore, while the maximum modulation of both the L- and M-cones along the achromatic axis are equal to 1.0, they are not equal to one another along the $\mathrm{L}-\mathrm{M}$ isoluminant axis. Furthermore, the maximum change in the excitation of the L- and M-cones along the isoluminant axis is limited because of the overlap of the cone spectral-sensitivity curves. The modulations for the L- and M-cones along the L-M axis for our display are 0.0834 and 0.159 . Therefore,

$$
\begin{aligned}
1\left(E l_{p}-90\right)= & \sin \left(2 \pi\left(E_{p}-90\right) / 360\right) \\
& +0.0834 \cos \left(2 \pi\left(E_{p}-90\right) / 360\right) \\
\mathrm{m}\left(E l_{p}-90\right)= & \sin \left(2 \pi\left(E_{p}-90\right) / 360\right) \\
& -0.159 \cos \left(2 \pi\left(E_{p}-90\right) / 360\right)
\end{aligned}
$$

Fig. 5 shows how the relative contributions of L- (upper curve) and M-cones (lower curve) vary with a cell's preferred elevation. The curves in Fig. 5 represent the behavior of red on-center cells and green off-center cells. The curves for red off-center and green on-center cells are the same, but with the signs reversed. A luminance mechanism (preferred elevation of $90 \mathrm{deg}$ ) combines L- and M-cone signals in a ratio of about 2:1. $\$$ Tuning to the isoluminant axis implies equal, opponent input from L- and M-cones. Relative cone weights change steeply with elevation around the achromatic axis and around the cone optimal directions, which in our color space are at $85.2 \mathrm{deg}$ for the L-cone and at $99.1(-80.9) \mathrm{deg}$ for the M-cone. Preferred elevations between $85.2 \mathrm{deg}$ and $90 \mathrm{deg}$, and between -80.9 deg and -90 deg, reflect synergistic input from Land M-cones; other elevations reflect opponent input.

Fig. 6 shows distributions of weights that different subclasses of red-green cell attach to modulations of L- and M-cone signals (to simplify comparisons all weights are shown as positive values). The median value for the center cone weight varies from 0.56 for green on-center cells to 0.63 for red off-center cells. This small difference belies interesting differences among the distributions. Green center cells have more equally balanced L- and M-cone weights than do red center cells, which attach more weight to inputs from the L-cones (compare rows in Fig. 6). The median value for the center cone weight is significantly higher for red center cells $(P<0.025)$. As was seen earlier in the comparison of elevations, the difference between red off-center and green oncenter cells is especially pronounced $(P<0.005)$. The difference between on- and off-center cells was also significant $(P<0.025)$ :

$\ddagger$ The conversion from preferred elevation to cone weight is relatively insensitive to the exact ratio in which $\mathrm{L}$ - and M-cone signals contribute to luminance: the central part of Fig. 5 would look essentially the same for different cone contributions to a luminance mechanism.

Fig. 4. Distributions of azimuth and elevation for 177 red-green P-cells. A: The spherical distribution plotted in an orthogonal coordinate system. Different symbols identify different subtypes of cell. White diamonds show the mean azimuths and elevations of the different subclasses. B: Distributions of azimuth and elevation shown separately for the four subtypes of red-green cells. Elevations in B are plotted without regard to sign. 


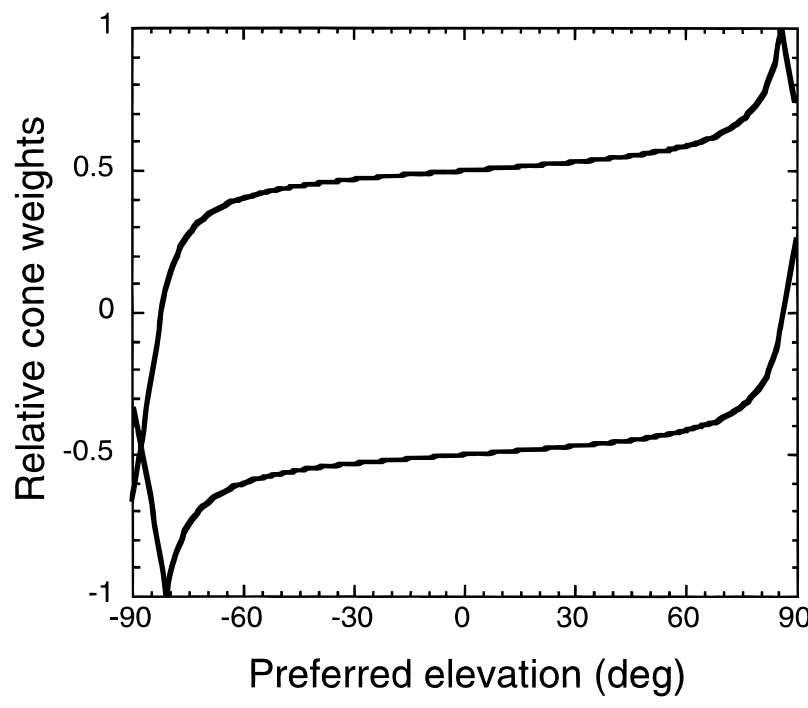

Fig. 5. Relative weights assigned to signals from L- and M-cones as a function of the preferred elevation of a cell. The curves are calculated from eqns. (2-5) (see text). The upper curve shows the L-cone weight; it peaks at the L-cone preferred direction $(-85.2 \mathrm{deg})$. The lower curve shows the M-cone weight and peaks at the M-cone preferred direction ( $-80.9 \mathrm{deg})$. Elevations between 0 and $85.2 \mathrm{deg}$ yield the weights for a red on-center cell; elevations between 0 and -80.9 deg yield the weights for a green off-center cell. Curves for red off-center and green on-center cells have the same shape, but the signs are reversed. The curves illustrate the nonlinear mapping of preferred elevations to cone weights.

off-center cells attach more weight to the cone class that drives the center (compare columns in Fig. 6).

\section{Discussion}

Among the red-green P-cells that receive inputs from only L- and M-cones, we found a broad range of preferred elevations. The strength of chromatic opponency varied among subclasses of cells: red center cells were tuned more narrowly to higher elevations than were green center cells (Fig. 3). Similar differences, though less pronounced, were also found for color tuning expressed in terms of the weights with which neurons combine inputs from Land M-cones. Red center cells assign relatively more weight to the center input from L-cones, and assign this weight with greater variability (Fig. 6). Cone weights vary neither linearly nor monotonically with preferred elevation, so one does not expect to see precisely the same picture in the two representations. Small differences in cone weights may cause large differences in preferred elevation (Fig. 5).

In associating a particular type of cone with the center of the receptive field, we have assumed (1) that the polarity of a cell's initial response to full-field illumination with achromatic light is determined by the center; (2) that a single cone type drives the center. The first assumption is true for all cells in which we have examined it; the second is justified by anatomical evidence that in and near the fovea a single cone drives the center of a P-cell's receptive field (Calkins et al., 1994). The relative cone weights are calculated from responses to full-field stimuli, and represent the weights of center and surround only if the surround draws its inputs from a single class of cone. To the extent that the surround draws inputs from both classes of cones (Lennie et al., 1991; Dacey \& Lee, 1995), our method underestimates the weight of the center.
The overall distribution of cone weights across all subclasses of red-green cells closely resembles that reported by Derrington et al. (1984), but apparently disagrees with that described by Smith et al. (1992), who found that to account for the phases of responses of P-cells to red-green flickering lights, the cells would have to combine L- and M-cone signals with weights ranged around the ratio 0.35:0.65, and differing little among subclasses of cells. The difference between studies is in fact to be expected, since the reported weights mean different things. We have estimated the weight assigned to the modulation of quantum catches, discounting the mean. Smith et al. estimated the weight assigned by a cell to the quantum catches in each class of cone; their average weights when converted to our measure would yield weights much like ours.

We found differences in temporal properties between on- and off-center cells, but no differences related to the type of cone driving the center. This observation suggests that different kinds of cones, and the pathways connecting them to P-cells, have comparable temporal properties. This agrees with measurements on cones (Boynton \& Baron, 1975; Schnapf et al., 1990), P-cells (Gielen et al., 1982; Smith et al., 1992), and psychophyscial observations that have examined flicker sensitivity in L- and M-cone systems (Estévez \& Spekreijse, 1974; Lennie, 1984). Differences among the chromatic properties of subclasses therefore probably result from different weights assigned to signals from different classes of cones.

Our results raise two interesting issues about retinal organization. First, how do different classes of cones come to have different weights in driving ganglion cells? Second, how do on- and offcenter cells come to have different temporal characteristics?

Differential weights of cone inputs driving a P-cell might arise from different numbers of cones driving the cell, and/or from different strengths of signals arriving from each cone. In the latter case, differences could reflect both fixed factors (for example, more efficient or more numerous synaptic connections) and variable ones (for example, gain adjustments that result from light adaptation). Because we do not know precisely how chromatic adaptation changes the relative gains in the different cone systems, we cannot be certain that the greater weight assigned to L-cone inputs in red center cells reflects some stable property of the retina. However, our cells were adapted to near equal-energy white light, and there is little reason to suppose that this biases sensitivity in favor of one or other cone system. Stable characteristics probably account for the greater weight assigned to L-cones, and probably reflect not greater numbers of L-cones but more effective connections. It is very likely that a single cone drives the center of the P-cell's receptive field. That being the case, having more L-cones than M-cones in the retina would not result in L-cone inputs having greater weight at the P-cell.

Calkins et al. (1994) recently described, within both on- and off-pathways, two circuits that can connect different cones to their midget ganglion cells. In one, a cone makes $32 \pm 3$ ribbon synapses with a midget bipolar cell, which in turn makes $28 \pm 4$ synapses with a midget ganglion cell. In the other, a cone makes $49 \pm 3$ synapses with a bipolar cell, which in turn makes $47 \pm 3$ synapses with a midget ganglion cell. Calkins et al. suggested that these systems originated separately in the L- and M-cones, although they could not establish which circuit was associated with which class of cone. Compared to the large differences in number of synapses, our observations show only small differences in the weights attached to L- and M-cone inputs, and therefore suggest that synapses in the two cone systems must differ substantially in their effectiveness. An alternative possibility is that one cone system is much more effective than the other, but that our measure- 


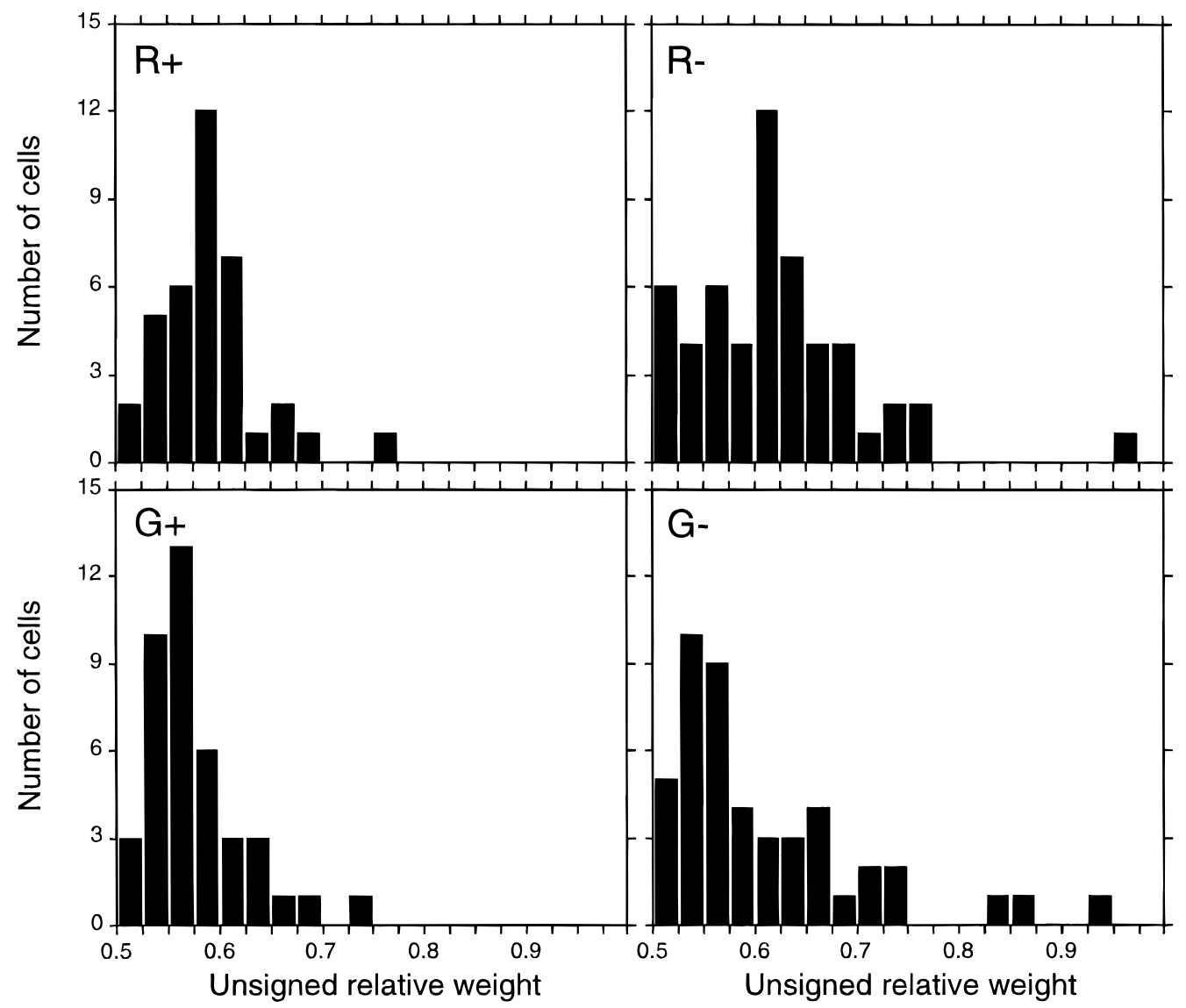

Fig. 6. Distributions of weights that different subclasses of red-green cells attach to inputs from L- and M-cones, derived from responses to $4 \mathrm{~Hz}$ modulation of spatially uniform fields along different directions in color space. The derivation of weights assumes that cells receive no inputs from S-cones. In each graph the abscissa shows the center cone weight, without regard to sign (which would be negative for off-center cells).

ments underestimate its effectiveness because they are insensitive to common input to center and surround. That is, if the receptivefield surround receives signals from both L- and M-cones (Lennie et al., 1991), the class that also provides the center signal could have substantial synaptic weight that is ultimately largely discounted by center-surround interaction. Were this the case, our observations point to the L-cone having the greater density of connections.

On- and off-center P-cells have different temporal characteristics, expressed in the phases of their responses to achromatic stimuli but not in their responses to isoluminant stimuli. In relation to its excitatory stimulus, the off-center cell responds to achromatic modulation with a greater phase lag that, if represented as a transport delay, implies an extra delay of $17 \mathrm{~ms}$. This is unlikely to be associated with the different kinds of synaptic connections that cones make with on- and off-bipolar cells. The second-messenger mediated channels for the sign-inverting synapse between receptors and on-center bipolar cells impose a delay not seen in the directly gated ion channels for the sign-conserving synapse between receptors and off-center bipolar cells (Shiells \& Falk, 1995). For rods, Shiells and Falk estimate this at about $10 \mathrm{~ms}$, but it is in the wrong direction to explain our results. Moreover, delays resulting from fundamentally different synaptic mechanisms would be unlikely to disappear with a change in the chromatic composition of the stimulus. Two factors distinguish the conditions under which on- and off-center cells behave differently: the signals evoked in the center and surround mechanisms are broadly out of phase for achromatic stimuli and in phase for isoluminant stimuli; the depth of modulation of cone excitations (and the amplitudes of the resulting center and surround signals) are usually larger for the achromatic stimuli than for isoluminant stimuli. The former seems an unlikely source of the difference between on- and off-center cells. An amplitude-dependent difference in dynamics would seem more probable, but experimental measurements of the phases of responses at different stimulus contrasts have so far revealed no sign of it (Benardete et al., 1992).

\section{Acknowledgments}

This work was supported by NIH Grants EY 04440, EY 01319, and EY06638.

\section{References}

Benardete, E.A., Kaplan, E. \& Knight, B.W. (1992). Contrast gain control in the primate retina: P-cells are not X-like, some $\mathrm{M}$ cells are. Visual Neuroscience 8, 483-486.

Boynton, R.M. \& BARON, W.S. (1975). Sinusoidal flicker characteristics of primate cones in response to heterochromatic stimuli. Journal of the Optical Society of America 65, 1091-1100.

Calkins, D.J., Schein, S.J., Tsukamoto, Y. \& Sterling, P. (1994). Mand L-cones in macaque fovea connect to midget ganglion cells by different numbers of excitatory synapses. Nature 371, 70-72. 
Croner, L.J. \& Kaplan, E. (1995). Receptive fields of P and M ganglion cells across the primate retina. Vision Research 35, 7-24.

DACEY, D.M. \& LEE, B.B. (1995). Physiological identification of cone inputs to $\mathrm{HI}$ and $\mathrm{HII}$ horizontal cells in macaque retina. Investigative Ophthalmology and Visual Science (Suppl.) 36, S3.

De Monasterio, F.M. \& Gouras, P. (1975). Functional properties of ganglion cells of the rhesus monkey retina. Journal of Physiology (London) 251, 167-195.

Derrington, A.M., Krauskopf, J. \& Lennie, P. (1984). Chromatic mechanisms in lateral geniculate nucleus of macaque. Journal of Physiology (London) 357, 241-265.

Derrington, A.M. \& Lennie, P. (1984). Spatial and temporal contrast sensitivities of neurones in lateral geniculate nucleus of macaque. Journal of Physiology (London) 357, 219-240.

De Valois, R.L., Abramov, I. \& Jacobs, G.H. (1966). Analysis of response patterns of LGN cells. Journal of the Optical Society of America 56, 966-977.

Dreher, B., Fukuda, Y. \& Rodieck, R.W. (1976). Identification, classification and anatomical segregation of cells with X-like and Y-like properties in the lateral geniculate nucleus of old-world primates. Journal of Physiology (London) 258, 433-452.

Estévez, O. \& SPeKreiJSE, H. (1974). A spectral compensation method for determining the flicker characteristics of the human colour mechanisms. Vision Research 14, 823-830.

Famiglietti, E.V., JR. \& Kolb, H. (1976). Structural basis for Onand Off-center responses in retinal ganglion cells. Science 194, 193 195.

Gielen, C.C.A.M., Ginsbergen, J.A.M. v. \& VendriK, A.J.H. (1982) Reconstruction of cone-system contributions to responses of colouropponent neurons in monkey lateral geniculate. Biological Cybernetics 44, 211-221.

Gouras, P. \& Zrenner, E. (1979). Enhancement of luminance flicker by color-opponent mechanisms. Science 205, 587-589.

JUDD, D.B. (1951). Basic correlates of the visual stimulus. In Handbook of Experimental Psychology, ed. STEvens, S.S., pp. 811-867. New York: Wiley.

Kaplan, E. \& Shapley, R.M. (1982). X and Y cells in the lateral geniculate nucleus of the macaque monkey. Journal of Physiology (London) 330, 125-144.

Kouyama, N. \& Marshak, D.W. (1992). Bipolar cells specific for blue cones in the macaque retina. Journal of Neuroscience 12, 1233-1252.

Krauskopf, J., Williams, D.R. \& Heeley, D.W. (1982). Cardinal directions of color space. Vision Research 22, 1123-1131.

Krauskopf, J., Williams, D.R., Mandler, M.B. \& Brown, A.M. (1986). Higher order color mechanisms. Vision Research 26, 23-32.
Lankheet, M.J.M., Lennie, P. \& Krauskopf, J. (1998). Temporalchromatic interactions in LGN P-cells. Visual Neuroscience 15, 47-54.

Lee, B.B., PoKorny, J., Smith, V.C., Martin, P.R. \& Valberg, A. (1990). Luminance and chromatic modulation sensitivity of macaque ganglion cells and human observers. Journal of the Optical Society of America A 7, 2223-2236.

Lennie, P. (1984). Temporal contrast sensitivities of red- and greensensitive cone systems in dichromats. Vision Research 24, 1995-1999.

Lennie, P., Haake, P.W. \& Williams, D.R. (1991). The design of chromatically opponent receptive fields. In Computational Models of Visual Processing, ed. Landy, M.S. \& Movshon, J.A., pp. 71-82. Cambridge, Massachusetts: MIT Press.

MacLeod, D.I.A. \& Boynton, R.M. (1979). Chromaticity diagram showing cone excitation by stimuli of equal luminance. Journal of the $O p$ tical Society of America 69, 1183-1186.

Padmos, P. \& Norren, D. v. (1975). Cone systems interaction in single neurons of the lateral geniculate nucleus of the macaque. Vision Research 15, 617-619.

Schnapf, J.L., NunN, B.J., Meister, M. \& Baylor, D.A. (1990). Visual transduction in cones of the monkey Macaca fascicularis. Journal of Physiology (London) 427, 681-713.

SHIELls, R. \& FALK, G. (1995). Signal transduction in retinal bipolar cells. Progress in Retinal and Eye Research 14, 223-247.

Sмith, V. \& Pokorny, J. (1975). Spectral sensitivity of the foveal cone photopigments between 400 and $500 \mathrm{~nm}$. Vision Research 15, 161-171.

Smith, V.C., Lee, B.B., Pokorny, J., Martin, P.R. \& Valberg, A. (1992) Responses of macaque ganglion cells to the relative phase of heterochromatically modulated lights. Journal of Physiology (London) 458, 191-221.

Stell, W.K., Ishida, A.T. \& Lightfoot, D.O. (1977). Structural basis for on- and off-center responses in retinal bipolar cells. Science 198, 1269_ 1271.

Valberg, A., Lee, B.B. \& Tryti, J. (1987). Simulation of response of spectrally opponent neurones in the macaque lateral geniculate nucleus to chromatic and achromatic stimuli. Vision Research 27, 867-882.

Webster, M.A. \& Mollon, J.D. (1991). Changes in colour appearance following post-receptoral adaptation. Nature 349, 235-238.

Wiesel, T.N. \& HubeL, D.H. (1966). Spatial and chromatic interactions in the lateral geniculate body of the rhesus monkey. Journal of Neurophysiology 29, 1115-1156.

Wooten, B.R. \& Werner, J.S. (1979). Short-wave cone input to the red-green opponent channel. Vision Research 19, 1053-1054.

Yeh, T., Lee, B.B. \& Kremers, J. (1995). Temporal response of ganglion cells of the macaque retina to cone-specific modulation. Journal of the Optical Society of America A 12, 456-464. 